University for Business and Technology in Kosovo

UBT Knowledge Center

UBT International Conference

2015 UBT International Conference

Nov 7th, 9:00 AM - 5:00 PM

\title{
The phenomena of Urban Sprawl - study case of city of Prishtina
}

Ilirjana Mejzini

University for Business and Technology, ilirjana.mejzini@ubt-uni.net

Follow this and additional works at: https://knowledgecenter.ubt-uni.net/conference

Part of the Architecture Commons

Recommended Citation

Mejzini, llirjana, "The phenomena of Urban Sprawl - study case of city of Prishtina" (2015). UBT

International Conference. 57.

https://knowledgecenter.ubt-uni.net/conference/2015/all-events/57

This Event is brought to you for free and open access by the Publication and Journals at UBT Knowledge Center. It has been accepted for inclusion in UBT International Conference by an authorized administrator of UBT Knowledge Center. For more information, please contact knowledge.center@ubt-uni.net. 


\title{
The phenomena of Urban Sprawl - study case of city of Prishtina
}

\author{
Ilirjana Mejzini \\ UBT- Higher Education Institution \\ ilirjana.mejzini@ubt-uni.net
}

\begin{abstract}
Urban sprawl is a phenomena that affected the entire world, in particular the capital cities. There are different cases and forms of the city extensions, which influence the community in many ways, like: social behaviour, economic prosperity, irrational land use, infrastructure disorder, energy inefficiency as well as polluted environment.

This paper explores ty pical examples of urban sprawl evident in European cities and the core reasons of its appearance. The analyses will focus on the rapid urban extension of Prishtina; it's over population and all consequences affecting daily life.

The aim of the paper is to highlight the most dangerous factors resulting in Prishtina's chaotic city development, in order to raise awareness among decision makers and other stakeholders to prevent further urban sprawl and find any potential possibilities for efficient and sustain urban solutions.
\end{abstract}

Keywords: urban sprawl, consequences in society, core of the city, land use, infrastructure, environment.

\section{Introduction}

Capital cities represent the biggest drivers of development; it's where infrastructure is more advanced, a higher density of productive population is present, a larger selection of schools, cinemas, theatres is possible... and simply where "everything happens". This of course has triggered migration of the rural population to the capitals, and is something which presently occurs and will continue in the future. These migrations result in the enlargement of existing habitats or in the urbanization of peripheral parts of the city, also known as urban sprawl.

Urban sprawl is a phenomenon which all cities face in all parts of the world. The definition of urban sprawl as "huge patches of once green country side turned into vast, smog-filled deserts that are neither city, suburb nor country", is a motive for urban planners to study this phenomenon with the objective of finding better solutions to the problem. Initially in this paper, an explanation of how urban sprawl is perceived, is provided, together with the main reasons why this phenomenon is present. Moreover, the main features characterizing urban sprawl and their consequences to the society, economy and environment are elaborated. Considering that Prishtina is a ty pical example of urban sprawl, a detailed study case is provided in a separate chapter. All possible factors that resulted in the urban chaos of Prishtina are analyzed. To trace the roots of the cause, the challenges facing the the city's governance over the years are briefly explained. As a consequence of various problems accumulated, the urban sprawl phenomenon was inevitable. The city not only expanded, but its urban areas actually exceeded city borders and spread to cadastral parcels of neighboring cities.

With the aim of investigating solutions, the last chapter elaborates on advanced and promising studies of effective urban expansion. Further, the mechanisms to halt urban sprawl are explained, together with modern trends of planning toward sustainable development of cities. 


\section{The meaning of urban sprawl}

\subsection{Definition}

The development of capital cities is a continual process determined by economic trends and modern way of life. This attracts populations of smaller towns and villages who view the capital as a place of more opportunity. On the other hand, how is it possible for a large city to absorb such huge increases in inhabitants? Without doubt the only viable solution is the city expansion.

Due to large migration fluxes, many metropolitan cities are faced with rapid urbanization, where the city expands in multiple directions. The city centers almost always become over-populated, while the density decreases as you move away. An inadequate visual image is one from an aerial photo at night, where the lights in the suburbs are less and further apart, yet as the center is approached they become denser until a huge bright area is created. The expansion of cities as it would be visible through this aerial image is known as urban sprawl. In common use, sprawl has become a pejorative term that seems to take a variety of meanings; quickly and cheaply built neighborhoods at the edge of metropolitan areas, architecturally monotonous residential subdivisions, or ugly feeder roads lined with strip malls. "Urban sprawl" was used for the first time by William H. Whyte in early 1958 in an article published in Fortune magazine. He observed that "huge patches of once green country side had been turned into vast, smog-filled deserts that are neither city, suburb nor country". In addition he warned about the great expansion of metropolitan areas where subdivisions of one city where beginning to meet up with the subdivisions of another. Furthermore, describing a particular form of urbanization, the term also relates to the social and environmental consequences associated with this development. Sprawl refers to a mixture of land uses occurring in an unplanned pattern and that is generally identified with outward sub urban growth of the city.

As population in a city grows beyond capacity, the local communities continue to spread farther and farther from city centers. However, regardless of how a city expands, the connection to its center remains crucial for all members of society. The urbanization of a city towards the rural suburbs is characterized by more spread-out infrastructure, larger distances from the city center, and much smaller density compared to urban areas. Apart from differences in density, these zones result in environmental and spatial issues, and together form a puzzle with concerning consequences that symbolizes the urban sprawl phenomenon.

\subsection{Features that characterize the urban sprawl phenomenon}

Figure 1 provides details for the specific characteristics of the urban sprawl phenomenon. The figure displays various categories of how a city centre developed and expanded towards rural areas, as:

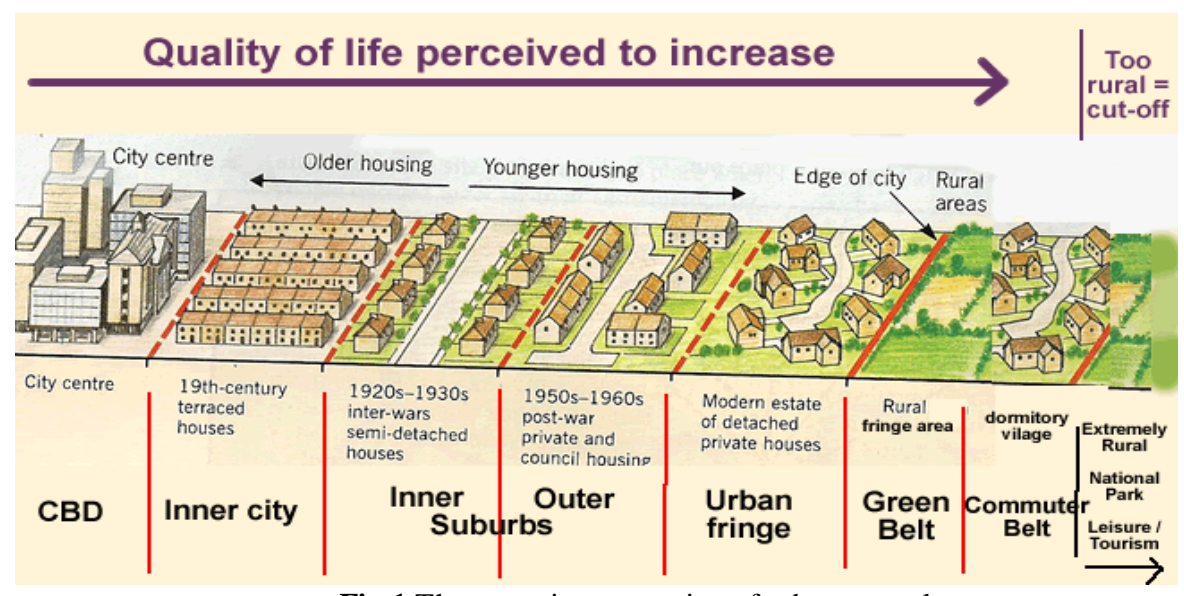

Fig.1 The extension categories of urban sprawl 
- City center, which dates back to when the urban area first appeared.

- Inner city, squeezed older housing, populated during $19^{\text {th }}$ century

- Suburbs (inner and outer y ounger housing) populated during the $20 \mathrm{~s}-60 \mathrm{~s}$ of the $20^{\text {th }}$ century

- Urban fringe, up to the edge of the city, modern estate

- Rural areas, green belt (rural fringe area) and commuter belt (dormitory village)

- Extremely rural - National Parks, leisure or tourism

At first glance it is perceived that the further away from the center one goes, the air is cleaner and general living conditions are better. Therefore urban sprawl is also caused by people in high income groups who have stronger preferences towards larger homes, more bedrooms, bigger balconies and bigger lawns. Generally, people look out for low-density residential areas where they can create a home according to their preferences. In addition, there are lower costs for land and houses, compared to higher prices as one gets closer to the city centers.

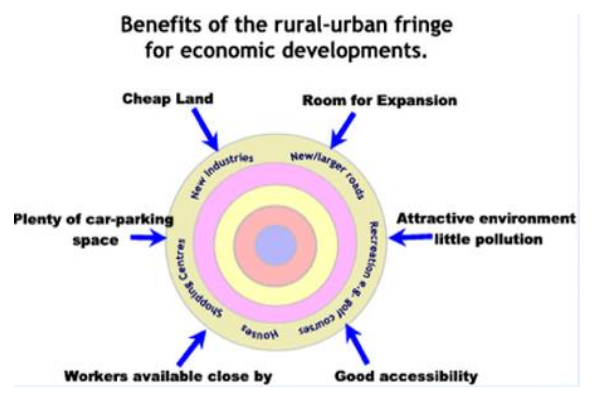

There are also other benefits of the rural-urban fringe for economic development such as:

- $\quad$ Room for expansion

- Attractive environment with little pollution

- $\quad$ New larger roads

- Plenty of car-parking space

- Good accessibility for huge recreational centers, shoppingmalls, innovative and high tech. industries

However, if seen through deeper empirical analysis, various issues can be observed that could result in huge changes to social, economic and environmental aspect of human life.

Development towards the suburbs results in more sporadic buildings which lead to less population density. The bigger the urbanization, the less there will be green areas. Areas of land that could be used for agriculture and forestry are gradually converted into construction areas which limit the cultivation of organic food. Another aspect is the poorer infrastructure compared to that of the center, where inhabitants are heavily reliant on commuting to fulfill their daily needs. The dependency on automotive vehicles results in higher expenses. Further, the excessive use of automotive vehicles no doubt increases $\mathrm{CO}_{2}$ emission and pollution of the area.

Moreover, further expansion of urban areas results in extremely extended land-use which may lead to an ecosystem imbalance and have negative impacts to normal living conditions.

To summarize the points raised above, the following list covers the main occurrences leading up to urban sprawl:

- $\quad$ huge neighborhoods only with residential buildings

- $\quad$ very low population density

- $\quad$ infrastructure extension

- $\quad$ extended land-use and loss of forests and agricultural land

- $\quad$ vehicle-dependent communities and larger transport expenses

- $\quad$ Increased Emission of CO2

- Ecosystem degradation 
The Urban sprawl phenomenon can be considered a puzzle composed of all of the above. Bearing in mind all the consequences to nature and human society, it is inevitable to search for solutions to tackle this phenomenon.

\section{Cas e study of Prishtina}

\subsection{What caused the urban sprawl of Prishtina}

Mass migration - Prishtina is an example of city enlargement. It represents the difficulties of the transformation process from a socialist to a market driven economv which can be identified in cities all over the Balkans, as well as reinvention of itself after a long period of oppression and the war of 98/99. Development demands in the post war Prishtina intensified when the rural population began streaming into the city. Within a brief period of time, Prishtina doubled its population, resulting in the speedy rebuilding of the city. The majority of postwar Prishtina inhabitants engaged in creation of new spaces for housing purpose, and some for their family businesses. Some engaged in building of more enhanced residences to improve their life style.

Lack of urban plans - The migration right after the conflict was that massive, that the need for construction resulted in chaotic urban development. Due to the lack of rule of law and incompetent management in the late 90s, the General Plan of Prishtina of 1985 was neglected completely. The local institutions of Kosovo had just been founded and considering the problems facing the post-war country, it became extremely difficult to draft new plans to accommodate the expansion of the city.

Low price of land - Considering that administration was also at its early phases, becoming a legal land estate owner was almost impossible. Over $70 \%$ of the city suburbs were once private or public agricultural land, but its conversion into land for construction was made possible by the Yugoslav administration through illegal procedures. Land, because it fell under construction parcels, became very cheap and becoming a land owner wasn't very difficult.

Low quality buildings - Due to a lack of construction standards and urban plans, unlicensed construction and buildings hardly complying with urban standards became very common. In almost every parcel, the maximum possible lay out was built, and basic principles of window opening, roof style and distance between buildings were almost entirely ignored.

Expensive prices of existing properties - Arbitrary prices of existing housing also had an effect on the expansion of the urban zone. The buildings in urban areas, built before 1989, all had complete documentation. However, due to enormous request for housing, prices were usually set without taking the estate aspect in to too much consideration. Therefore, the most feasible solution seemed to be new buildings which unavoidably extended urban areas in all directions.

\subsection{Urban extension of Prishtina in the past}

Not only Prishtina but almost all cities and towns of Kosovo are characterized by uncontrolled urban development in suburb areas. Considering the lack of consistent administration, every new government would inherit varying jurisdiction. After WW2, Prishtina extended based on new plans which ignored the traditional urban core and cultural and historical image build throughout centuries. Up until 1989, when the disintegration of Yugoslavia began, only a small portion of the city center was regulated under urban plans, while the surrounding areas were urbanized in an arbitrary and uncontrolled manner. The use of land was far from efficient, considering that only around a quarter of the urban area contended collective housing. Like the traditional areas, the new neighborhoods mostly consisted of individual housing.

The year 1999 found Prishtina in a desperate state after years of occupation. Not only had anything been built, but the existing buildings were neither adopted nor renovated to meet the inhabitants' needs. This stagnation on one hand, and the ever increasing requirements of the community, brought Prishtina to a reality where almost the whole city was turned into a construction site. Further, even the most rural places of Prishtina began to be urbanized not only from their inhabitants, but also the population migrating from all parts of Kosovo. Within a period of 15 years, the existing urban area trebled to contribute to a ty pical urban sprawl with all the negative aspects that associate it. 


\subsection{Characteristics of Prishtina's urban spraw}

Urban developments that resulted in the expansion of urban areas mostly came from private rather than public investment. Public investment focused on collective housing and was largely based on an urban plan. Considering they were in limited numbers, they were mostly built in convenient parts of the suburbs that were close to the center and had good access to the existing infrastructure. Private investment however, manifested in huge numbers which made it difficult to plan location and also ensure they all possessed licenses due to insufficient urban plans.

A characteristic of private investment was that the moment a piece of land was secured; investment would be realized, regardless of access to infrastructure, the distance to the center, or the density. The investment were based only in possessed financial capacity, often in middle of agricultural land, without basic infrastructure, or any access to existing road net. This phenomenon was also seen in the cases of capital investments in industrial buildings and large blocks of collective buildings.

In many cases, after the urbanization of a suburb area, there were efforts to draft an urban plan with the aim of adapting to the situation at hand. This demonstrates that a key characteristic of urban sprawl in Prishtina was the fact that urbanization would happen before any actual planning. Therefore, the main decision-makers of Prishtina's urban extensions were and continue to be businessmen in construction. Regretfully, this is done with minimum consideration to other planning factors such as: effective land use, social welfare or rational use of infrastructure, let alone attention to green environment.

With urbanization of land, the infrastructure would typically be extended from the center through existing networks but without actually increasing capacity. This would result in serious problems such as sewage issues due to the networks limited capacity and unmaintained facilities.

As a result of the aforementioned chaotic expansions, the urban sprawl of Prishtina is different to other categories of urban sprawl. Further, it is rather difficult to differentiate a beginning and an end between the city and the expansion to suburban and rural areas. The urban unit of Prishtina itself, with its numerous expansions is fairly spread out, where parts of this expansion have almost merged with neighboring towns and villages; the international village adjacent to Ajvali, the NIC neighborhood in Cagllaviva or Marigona between Prishtina, Fushe-Kosova and Lipjan.

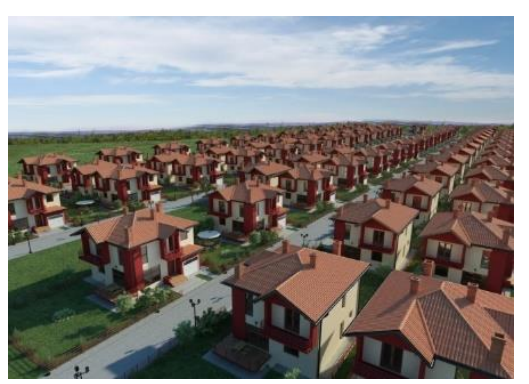

Fig.3 Mono-functional "NIC Residence"

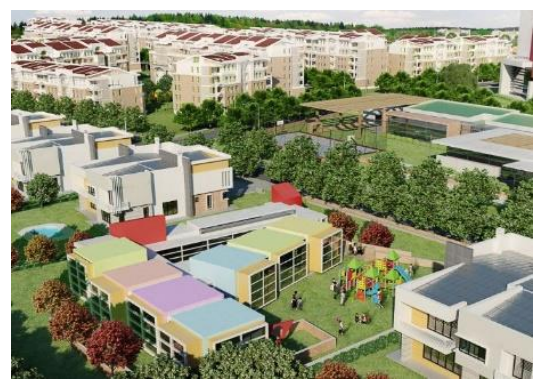

Fig.4 Multi-functional "Marigona Residnce"

New and modern neighborhoods are built with sophisticated building standards, but very little attention is dedicated to urban adaption and the social welfare of the community. With the exception of Marigona neighborhood, which is built based on modern standards of multi-functional planning, the other neighborhoods are simply housing residents, also known as mono-functional.

However, their distance of about $10 \mathrm{~km}$ from Prishtina makes them serious contributors to urban sprawl through: car-dependent communities, extraordinary extended infrastructure, non-efficient land-use, limitation of agricultural land, and far from environmentally friendly city development. 


\section{Challenges for overcoming urban sprawl}

\subsection{Contemporary planning}

In contrast of old planning in the past, which concentrated on improving the physical aspects of buildings and streets. modern citv planning is increasinglv concerned with the social and economic aspects of city living. The process of city planning is a highly complex, step-by-step procedure, usually involving a series of surveys and studies, development of a land-use plan and transportation plan, preparation of a budget, and ap proval of a unified master plan by various agencies or legislative bodies. City planners are usually part of an urban planning board or governmental agency that must take into account the characteristics and long-range welfare of the people of a particular urban community - their employment opportunities, income levels, need for transportation, schools, shopping areas, hospitals, parks and recreational facilities. They must face the problems of traffic, congestion, and pollution; they must also consider the availability of police, fire, and sanitation services, the limitations posed by zoning and other regulations, and the problems of funding. In recent vears. residents of manv communities have demanded greater participation in the planning of their own neighborhoods, and some planners have worked closely with community groups during various stages of the planning process.

Principles of intelligent urbanism - is a theory of urban planning composed of a set of axioms intended to guide the formulation of city plans and urban designs. They are intended to reconcile and integrate diverse urban planning and management concerns. by including economic. social and environmental sustainability. The term was coined by Prof. Christopher Charles Benninger.

The axioms for intelligent urbanism contain these principles: balance with nature and tradition; appropriate technology; conviviality (places for individuals, friendship, householders, neighborhood and communities); efficiency; regional integration and institutional integrity, Benninger. Ch (2001).

\subsection{Urban consolidation - Adaptive re-use of areas within the urban zone}

Urban consolidation has been strongly tied to the green movement, which argues that urban sprawl leads to longer commutes and therefore more carbon emissions. Through urban consolidation, planners aim to pass laws limiting urban sprawl, as well providing incentives for developers to build and restore land within the downtown core. The methods of urban consolidation would limit urban sprawl by using existing areas more rationally and by adapting them for future re-use. The advantages this brings are numerous:

1. Economic aspect - lower cost since there is less need for infrastructure extension;

2. Social aspect - the community benefits from the proximity to the center and isn't isolated in less dense areas;

3. Environmental aspect - less carbon emission as a result of more walking distance services.

The fulfillment of the three aforementioned aspects is a valid reason for planners to consider this an effective method. However, further investigation into alternative mechanism should be made, considering the fact that more complex solutions may be required for already dense zones. In available parcels in the center, it is not recommended to build very large buildings as it may cause overpopulation and potential disproportion with existing buildings. Further, the existing infrastructure would be unable to accommodate this large addition. During the adaption of existing zones for re-use it is vital that the existing urban harmony is preserved.

For adaptive re-use of urban zones it is very important that all stakeholders contribute in the process of planning, in particular the community that lives there. In this way, it will be easier for planners to identify the needs of the community and guide the adaption of the zone in the right direction. It is also essential that all relevant resources are taken into account, in particular built heritage. Its conservation and adaption would enable their use for the good of the community and also enable the preservation of historical and culture values for future generations. 


\section{Conclusion}

The analy sis of the urban sprawl phenomenon made it possible to identifv numerous cons equences for living species and nature. It can be concluded that the the farther the urban expansion, the larger the impact of pollution, energy inefficiency and $\mathrm{CO} 2$ emission.

On the one hand, as a result of the study of the causes of urban sprawl, it was evident that the lack of application of spatial planning principles and adequate mechanisms to prevent it, only helped the phenomenon expand. This expansion leads to inefficient land-use and loss of agricultural land which could gradually affect the ecosystem equilibrium.

The third chapter elaborated on the case study of the city of Prishtina, as an appropriate example where all major negative effects of urban sprawl are evident due to the urban chaos throughout the city. Further, the general circumstances present in Kosovo, and in particular Prishtina, that prevented previous planning were highlighted. As expected, this inefficieny in planning resulted in concerning consequences such as:

- Loss of agricultural land - resulting from sporadic inhabitance (while the overall density is very large in Kosovo);

- High emission of CO2 - resulting from the creation of neighborhoods located a good distance awav from the center.

Adequate solutions to tackle urban sprawl and limit its consequences have been investigated from international think tanks and most credible universities worldwide. Profesor Benninger's analysis concluded that intelligent urbanism would bring a balance in nature and tradition; appropriate technology; conviviality (places for individuals, friendship, householders, neighborhood and communities); efficiency; regional integration and institutional integrity. In the case of Prishtina, intelligent urbanism would undoubtebly help to decrease urban sprawl and at the same time, boost the consolidation of entire city in all aspects of sustainable development.

For adaptive re-use of urban zones it is crucial that all stakeholders are involved from the beginning of the planning process, in particular the community that lives there. In this way, it will be easier for planners to identify the needs of the community and guide the adaption of the zone in the right direction. It is also essential that all relevant resources are taken into account, in particular built heritage. Its conservation and adaption would enable their use for the good of the community and also enable the preservation of historical and culture values for future generations.

\section{References}

1. Bhatta, B (2010), Analysis of Urban Growth and Sprawl

2. Rafferty, J.P. (2006), Urban Sprawl

3. Hather, C. (2008), Urban consolidation - Its impact on sense of place

4. Lehman, S. (2011), Transforming the City for Sustainability: The Principles of Green Urbanism

5. Powell, K. (1999), Architecture Reborn: Converting Old Buildings for New Uses

6. El-Hissi, Sh. J. (2010), Urban Consolidation

7. Beder, Sh. (1996), The Nature of Sustainable Development, 2nd ed. Scribe, pp. 161-3

8. Kaji, H.; Kanegae,; H. Ishibashi, K.; Hara, N. (2003), Compact City and Developing Countries 9. Mejzini, I.A. (2012), The advantages of cross-border cooperation towards sustainable developments of Western Balkans, European Magazine, pg. 27

10. Vockler, K.; Jerliu, F. (2012), The City Transition: Archis Interventions in Prishtina, European Magazine, pg. 32 